\title{
Successful treatment of auditory hallucinations in a schizophrenia patient with the use of clonidine
}

\author{
Muhammed Hakan Aksu' ${ }^{1}$, Zehra Arikan ${ }^{2}$ \\ ${ }^{1}$ Yenimahalle Teaching and Research Hospital, Yildirim Beyazit University, Department of Psychiatry, Ankara - Turkey \\ ${ }^{2}$ Gazi University, Department of Psychiatry, Ankara - Turkey
}

\section{ABSTRACT}

Many reports show evidence of the disruption of central noradrenergic activity in the etiology of schizophrenia. A few studies show positive effects of a specific $a_{2}$-agonist, clonidine, on cognition and on positive and negative symptoms of schizophrenia. In this report, we tried clonidine for the treatment of auditory hallucinations in a patient with schizophrenia who had low compliance with antipsychotic treatment. At the end of seven days, auditory hallucinations decreased dramatically. Moreover, almost all auditory hallucinations disappeared at 6-months follow-up. This is the first case report showing the efficacy of clonidine monotherapy on auditory hallucinations in schizophrenia. However, the mechanism of action of clonidine remains hypothetical. The dramatic improvement observed in this case in the absence of any adverse effects suggests that controlled trials of the effect of clonidine on auditory hallucinations may be of clinical importance.
\end{abstract}

Keywords: Auditory hallucinations, clonidine, schizophrenia

\section{INTRODUCTION}

Auditory verbal hallucinations are subjective perceptions of external speech in the absence of external stimuli. They are strongly related with schizophrenia, being one of the most commonly seen symptoms. Their one-month prevalence is around $70 \%$. Auditory verbal hallucinations are relatively heterogeneous, varying from simple comments to explanations, from familiar voices to unknown ones, or from passive discussions to specific commands. They are generally intrusive, undesired, and distressing, and in around one in three patients, the condition is resistant to pharmacotherapy (1).

There is evidence in the literature suggesting that a central mechanism in the etiology of schizophrenia is a dysfunction of noradrenergic activity $(2,3)$. Noradrenalin is one of the important neurotransmitters in cognitive processes, especially in the prefrontal cortex (4). In the literature, there is ample evidence indicating noradrenergic involvement in cognitive deficits frequently found in schizophrenic patients $(2,5,6)$.

Noradrenergic neurons project from the locus coeruleus to the prefrontal cortex, where attention and working memory are modulated by noradrenalin. Noradrenalin, binding to $\alpha_{2}$ receptors (or more specifically, $a_{2 \mathrm{~A}}$ receptors), facilitates cognitive functions. When presynaptic $\alpha_{2}$ receptors are activated, noradrenergic release to the prefrontal cortex is reduced. At the same time, $\alpha_{2 \mathrm{~A}}$ receptors are located postsynaptically in the prefrontal cortex, and

How to cite this article: Aksu MH, Arikan Z. Successful treatment of auditory hallucinations in a schizophrenia patient with the use of clonidine. Dusunen Adam The Journal of Psychiatry and Neurological Sciences 2019;32:271-274.

Correspondence: Muhammed Hakan Aksu, Yenimahalle Teaching and Research Hospital, Yildirim Beyazit University, Department of Psychiatry, Ankara - Turkey

Phone: +90 3125872136 E-mail: mhknks@gmail.com

Received: May 09, 2019; Revised: June 12, 2019; Accepted: July 03, 2019 
there is strong evidence for positive effects of their activation on cognitive functions. For $\alpha_{1}$ receptors to be activated like $\alpha_{2}$ receptors, higher noradrenalin levels (e.g., during stress) are needed, and their longterm activation affects cognitive functions negatively. Increased noradrenergic transmission, as reported in schizophrenia, may cause a number of cognitive function disorders. Comprehensive evidence demonstrates that selective $\alpha_{2}$ agonists like clonidine can restore the equilibrium of $\alpha_{1}$ and $\alpha_{2}$ activity in the prefrontal cortex by reducing noradrenalin levels through activation of postsynaptic $\alpha_{2 \mathrm{~A}}$ receptors in the prefrontal cortex and presynaptic $\alpha_{2 \mathrm{~A}}$ receptors in the locus coeruleus. Therefore, Kruiper et al. (7) suggested that $\alpha_{2}$ agonists could improve cognition in schizophrenic patients.

In addition to a disruption of central noradrenergic activity in schizophrenia, it has also been shown that prepulse inhibition of the startle reflex (PPI) is reduced in these patients, indicating a problem with sensorimotor gating, a mental filter function related to the processing of external stimuli for conversion to a response (4). From a clinical perspective, it is believed that deficits in filtering sensory information lead to cognitive disruption and eventually hallucinations and delusions. One study showed that in schizophrenic patients, the addition of a small dose of clonidine to their stable medication was able to normalize effectively the deficient sensorimotor gating. Therefore, normalization of prepulse inhibition in schizophrenic patients may play a determinant role in the improvement of cognitive structures and symptoms (4).

In the first years of studying noradrenergic involvement in schizophrenia, researchers mainly focused on the effects of clonidine as a specific $\alpha_{2}$ agonist used as monotherapy or in combination with antipsychotics. Those studies demonstrated that the effect of clonidine was not limited to improving cognition, but at the same time positively affected positive and even negative symptomatology $(4,8-10)$. For unknown reasons, these studies were not followed up, and it appears that until recently, researchers had lost interest in the noradrenergic system (4).

By contrast, clonidine is being used in a large number of psychiatric disorders. It has been licensed by the FDA for the treatment of attention deficit hyperactivity disorder, and it has been used successfully in long-term opiate detoxification, post-traumatic stress disorder, and Tourette syndrome. Furthermore, clonidine is useful in the treatment of neuroleptic- induced akathisia, stimulant-induced insomnia, and clozapine-induced sialorrhea (11).

In the light of these findings, we chose clonidine for a schizophrenic patient with auditory hallucinations.

\section{CASE}

The patient was a 42-year-old woman, high school graduate, divorced, and not working.

She reported to our policlinic with complaints of hearing voices, being controlled, and feeling unease, anhedonia, and pessimism. Every day and almost all day long, she heard the voice of an unknown man, and she stated that this person had taken control of her left eye and left hand, while insulting and demeaning her. There were signs of anxiety, agitation, depression, and insomnia secondary to delusion and hallucinations.

During mental examination, hallucinations, delusions of being controlled, anxious mood, and an increase in the range of emotions were established. The patient had no insight.

Her complaints had begun 7 years earlier with hearing voices and delusions of being controlled and of persecution. Before reporting to our policlinic, she had undergone antipsychotic treatment intermittently for no more than 2 months. The patient had discontinued therapies with olanzapine, haloperidol, risperidone, and clozapine due to galactorrhea, weight gain, and extrapyramidal side effects.

Her family history revealed that her father, her younger sister, and her 12-year-old son had been diagnosed with schizophrenia.

She was diagnosed with schizophrenia according to the diagnostic criteria of the DSM-5.

Her scores were 40/16 on the Psychotic Symptom Rating Scales (PSYRATS), 25/22/59 on the Positive and Negative Syndrome Scale (PANSS), 15 on the Calgary Depression Scale for Schizophrenia (CDSS), and 25 on the Hamilton Anxiety Rating Scale (HAM-A).

The patient, who had not used medication for 3 months, was started on $6 \mathrm{mg}$ Paliperidone, gradually increased to $12 \mathrm{mg}$. At 8 -weeks follow-up, the scores were not significantly reduced (PSYRATS 37/15, PANSS 23/20/51, CDSS 14, HAM-A 25) and the patient had gained $6 \mathrm{~kg}$, leading to a decline in compliance.

Subsequently, treatment was changed to aripiprazole. Four weeks after the change, a final dose of $30 \mathrm{mg}$ was used for 12 weeks. Although the symptoms improved significantly (PSYRATS 22/11, PANSS 14/16/32, CDSS 11, HAM-A 20), patient compliance deteriorated due to continued weight gain. 
As the patient rejected the options of clozapine and long-acting depot antipsychotics, clonidine pharmacotherapy was recommended. Treatment was started with the doses used by Dardennes et al. (12) in the case of a clozapine-resistant schizophrenic patient (75-225 $\mu \mathrm{g})$.

After 7 days, a dramatic reduction of the patient's auditory hallucinations was observed. At 6-months follow-up, auditory hallucinations had resolved almost completely. The patient stated that the person whose voice she used to hear was no longer talking and could not control her hand and eye. Delusions of being controlled and symptoms of anxiety and insomnia had receded significantly. Social withdrawal and depressed mood showed partial improvement. Her scores were $16 / 9$ on PSYRATS, $12 / 17 / 29$ on PANSS, 10 on CDSS, and 16 on HAM-A. However, there was no significant change in insight. A reduction in the emotional component of the delusions was observed. The patient had been informed about frequently seen side effects such as hypotension, headache, stomachache, sedation, diarrhea, and constipation (13). No side effects were observed. Arterial blood pressure was measured weekly during the first month and subsequently monthly, showing normal levels. Unfortunately, despite the successful outcome of the clonidine treatment, it is hard for our treatment team to present a clear view about the option of returning to antipsychotic treatment and maintenance treatment.

\section{DISCUSSION}

While we could not diagnose our patient's schizophrenia as treatment-resistant, we can speak of resistance with regard to drug compliance. After using 3 different antipsychotics, including olanzapine, in an effective dose for an effective period of time, a significant reduction of her symptoms was achieved. However, due to weight gain, galactorrhea, and extrapyramidal side effects, the patient had discontinued the medication. For similar reasons, she did not show due compliance when trying clozapine. Antipsychotics are an important intervention strategy in schizophrenia (14). Similarly, it has been pointed out that antipsychotic drugs are effective in the treatment of auditory hallucinations in schizophrenic patients (15). In addition, transcranial magnetic stimulation or electroconvulsive therapy are used in resistant cases (15). In our case, due to the patient's problems with continuity and compliance, the abovementioned alternative treatments were applied.
In order to study the antipsychotic effects of clonidine, Freedman et al. (9) compared the effects of placebo, clonidine, and standard neuroleptic drugs in 1 schizoaffective and 7 schizophrenic patients, using a double-blind cross-over design, finding the same mean degree of improvement with clonidine and neuroleptics. Lechin et al. (16) successfully used clonidine in the treatment of patients with residual schizophrenia who had developed a relapse after withdrawal of regular treatment. Lerner et al. (17) tried clonidine in the treatment of hallucinatory "flashbacks" experienced by LSD users. After adding clonidine to the treatment of a clozapine-resistant schizophrenic patient, Dardennes et al. (12) reported a significant improvement in negative and positive symptoms. As in our case, within days they observed a dramatic response in the auditory hallucinations.

The effect mechanism of clonidine remains hypothetical. Evidence for the antipsychotic efficacy of clonidine is seen at the level of case reports. Due to the limitations of the available research, there is no strong evidence showing that the use of clonidine together with antipsychotic drugs achieves better results than the use of antipsychotics on their own. Controlled studies are needed to increase the reliability of data about the antipsychotic efficacy of clonidine.

To our knowledge, this is the first case report to show the effectiveness of clonidine monotherapy for auditory hallucinations in schizophrenia. In our case, we observed a dramatic improvement without any side effects, which shows that in particular circumstances, a controlled study of the use of clonidine in the treatment of auditory hallucinations in schizophrenic patients may be of clinical relevance.

\begin{tabular}{|c|c|c|}
\hline \multicolumn{2}{|c|}{ Contribution Categories } & \multirow{2}{*}{$\begin{array}{l}\text { Author Initials } \\
\text { M.H.A. }\end{array}$} \\
\hline \multirow{4}{*}{ Category 1} & Concept/Design & \\
\hline & Literature review & M.H.A., Z.A. \\
\hline & Data analysis/Interpretation & M.H.A. \\
\hline & Case follow-up (if applicable) & M.H.A. \\
\hline \multirow{2}{*}{ Category 2} & Drafting manuscript & M.H.A. \\
\hline & Critical revision of manuscript & Z.A. \\
\hline Category 3 & Final approval and accountability & M.H.A., Z.A. \\
\hline \multirow{2}{*}{ Other } & Technical or material support & M.H.A. \\
\hline & Supervision & Z.A. \\
\hline
\end{tabular}

Informed Consent: Written informed consent was obtained from the patient for the publication of the case report.

Peer-review: Externally peer-reviewed.

Conflict of Interest: The authors declare that they have no conflict of interest. 
Financial Disclosure: The authors declared no financial support.

\section{REFERENCES}

1. Tracy DK, Shergill SS. Mechanisms underlying auditory hallucinations-understanding perception without stimulus. Brain Sci 2013; 3:642-669. [Crossref]

2. Yamamoto K, Hornykiewicz O. Proposal for a noradrenaline hypothesis of schizophrenia. Prog Neuropsychopharmacol Biol Psychiatry 2004; 28:913-922. [Crossref]

3. Powchik P, Davidson M, Haroutunian V, Gabriel SM, Purohit DP, Perl DP, Harvey PD, Davis KL. Postmortem studies in schizophrenia. Schizophr Bull 1998; 24:325-341. [Crossref]

4. Oranje B, Glenthoj BY. Clonidine normalizes sensorimotor gating deficits in patients with schizophrenia on stable medication. Schizophr Bull 2013; 39:684-691. [Crossref]

5. Friedman JI, Adler DN, Davis KL. The role of norepinephrine in the pathophysiology of cognitive disorders: potential applications to the treatment of cognitive dysfunction in schizophrenia and Alzheimer's disease. Biol Psychiatry 1999; 46:1243-1252. [Crossref]

6. Litman RE, Pickar D. Noradrenergic systems: a target for augmenting pharmacotherapy: In Breier A (editor). The New Pharmacotherapy of Schizophrenia. Washington: American Psychiatric Press, 1996, 133-152.

7. Kruiper C, Glenthoj BY, Oranje B. Effects of clonidine on MMN and P3a amplitude in schizophrenia patients on stable medication. Neuropsychopharmacology 2019; 44:1062-1067.

8. Maas JW, Miller AL, Tekell JL, Funderburg L, Silva JA, True J, Velligan D, Berman N, Bowden CL. Clonidine plus haloperidol in the treatment of schizophrenia/psychosis. J Clin Psychopharmacol 1995; 15:361-364. [Crossref]
9. Freedman R, Kirch D, Bell J, Adler LE, Pecevich M, Pachtman E, Denver P. Clonidine treatment of schizophrenia: double-blind comparison to placebo and neuroleptic drugs. Acta Psychiatr Scand 1982; 65:35-45. [Crossref]

10. Fields RB, Van Kammen DP, Peters JL, Rosen J, Van Kammen WB, Nugent A, Stipetic M, Linnoila M. Clonidine improves memory function in schizophrenia independently from change in psychosis. Preliminary findings. Schizophr Res 1988; 1:417-423.

11. Naguy A. Clonidine use in psychiatry: panacea or panache. Pharmacology 2016; 98:87-92. [Crossref]

12. Dardennes RM, Al Anbar NN, Rouillon F. Successful augmentation of clozapine-resistant treatment of schizophrenia with clonidine. Prog Neuropsychopharmacol Biol Psychiatry 2010; 34:724-725. [Crossref]

13. Yasaei R, Saadabadi A. Clonidine. StatPearls [Internet]. Treasure Island FL; StatPearls Publishing, 2019.

14. Wlodarczyk A, Szarmach J, Cubala WJ, Wiglusz MS. Benzodiazepines in combination with antipsychotic drugs for schizophrenia: GABA-ergic targeted therapy. Psychiatr Danub 2017; 29(Suppl.3):345-348.

15. Sommer IE, Slotema CW, Daskalakis ZJ, Derks EM, Blom JD, van der Gaag M. The treatment of hallucinations in schizophrenia spectrum disorders. Schizophr Bull 2012; 38:704-714. [Crossref]

16. Lechin F, van der Dijs B, Gomez F, Valls JM, Acosta E, Arocha L. Pharmacomanometric studies of colonic motility as a guide to the chemotherapy of schizophrenia. J Clin Pharmacol 1980; 20:664-671. [Crossref]

17. Lerner AG, Finkel B, Oyffe I, Merenzon I, Sigal M. Clonidine treatment for hallucinogen persisting perception disorder. Am J Psychiatry 1998; 155:1460. [Crossref] 